Article

\title{
Thermal Pre-Treatment of Polymetallic Nodules to Create Metal (Ni, Cu, Co)-Rich Individual Particles for Further Processing
}

\author{
Anna V. Wegorzewski ${ }^{1, *}$, Martin Köpcke ${ }^{2}$, Thomas Kuhn ${ }^{1}$, Maria A. Sitnikova ${ }^{1}$ \\ and Hermann Wotruba ${ }^{2}$ \\ 1 Federal Institute for Geosciences and Natural Resources (BGR), Stilleweg 2, D-30655 Hannover, Germany; \\ Thomas.Kuhn@bgr.de (T.K.); MariaAlexandrovna.Sitnikova@bgr.de (M.A.S.) \\ 2 Unit of Mineral Processing, RWTH Aachen University, Lochnerstr. 4-20, Haus C, D-52064 Aachen, Germany; \\ martin@koepcke-ac.de (M.K.); wotruba@amr.rwth-aachen.de (H.W.) \\ * Correspondence: Anna.Wegorzewski@bgr.de
}

Received: 30 September 2018; Accepted: 25 October 2018; Published: 11 November 2018

\begin{abstract}
Polymetallic nodules are a potential source of industrially demanded metals such as $\mathrm{Ni}, \mathrm{Co}, \mathrm{Cu}$, and Mo (up to $3 \mathrm{wt} \%$ ). Even if there is no deep-sea mining of manganese nodules today, a forecasted gap between metal demand and supply as well as continuously high metal prices may make seabed mining economically viable in the future. Up to now, a well-established industrial-scale extraction method for manganese nodules has been missing. Therefore, the aim of this study is to explore how economically interesting metals can be extracted from the nodules in a cost- and energy-efficient way. Polymetallic nodules have a heterogeneous chemical and structural composition without individual metal-rich particles. The economically interesting metals are distributed between different mineral phases (Mn-Fe-(oxy)hydroxides) as well as different growth structures that are intergrown with each other on a nm- $\mu \mathrm{m}$ scale. Because of that a typical ore processing with the beneficiation of valuable particles is not feasible. The process presented here starts with a pyro-metallurgical pre-treatment of the polymetallic nodules, with the aim of creating artificial metal-rich $(\mathrm{Ni}, \mathrm{Cu}, \mathrm{Co}, \mathrm{Mo})$ particles with enrichment factors up to 10 compared to the original average metal contents. Afterwards, these particles should be beneficiated by conventional mineral processing steps to create a concentrate while reducing the mass stream in the process. The resulting metal particles can be further treated in conventional hydrometallurgical and/or pyro-metallurgical processes.
\end{abstract}

Keywords: polymetallic nodules; metallurgical treatment; nickel; copper; cobalt

\section{Introduction}

Polymetallic nodules occur at the sea floor of the Pacific, Atlantic, and Indian Ocean in water depth between 1000 and $6000 \mathrm{~m} \mathrm{[1-7].}$

Detailed German exploration of nodules began in the early 1970s with the vessels Valdivia II (1972-1978) and SONNE (up to 1982) because of the economic interest in nodules due to their metal content. Nodules are enriched in $\mathrm{Ni}, \mathrm{Cu}, \mathrm{Co}, \mathrm{Mn}, \mathrm{Li}, \mathrm{V}$, and $\mathrm{Mo}$ as well as rare earth elements and $\mathrm{Y}$ (REY; Table 1); because of the many metals, they are also called polymetallic nodules [8,9]. 
Table 1. Average chemical composition (wt \%) of polymetallic nodules from the eastern German license area within the Clarion and Clipperton Zone (CCZ; $N=741$; data from the Federal Institute for Geosciences and Natural Resources (BGR)).

\begin{tabular}{ccccccccccccccccc}
\hline $\mathbf{M n}$ & $\mathbf{F e}$ & $\mathbf{S i}$ & $\mathbf{A l}$ & $\mathbf{M g}$ & $\mathbf{C a}$ & $\mathbf{K}$ & $\mathbf{N a}$ & $\mathbf{N i}$ & $\mathbf{C u}$ & $\mathbf{C o}$ & $\mathbf{Z n}$ & $\mathbf{T i}$ & $\mathbf{M o}$ & $\mathbf{V}$ & $\mathbf{L i}$ & $\mathbf{R E Y}$ \\
\hline 31.1 & 6.2 & 6.1 & 2.3 & 1.9 & 1.7 & 1.0 & 2.2 & 1.4 & 1.2 & 0.17 & 0.15 & 0.26 & 0.06 & 0.06 & 0.01 & 0.07 \\
\hline
\end{tabular}

The interest in polymetallic nodules persisted up to the mid-1980s but, with metal prices dropping on the global markets, interest in nodules decreased, too. However, because of the increasing demand for and consumption of economically important metals, the interest in polymetallic nodules increased again after the turn of the millennium. Germany needs to import valuable metals ( $\mathrm{Ni}, \mathrm{Cu}, \mathrm{Mn}, \mathrm{Mo}$, REEs) for high-technology applications, the green-tech industry, the electronic industry, and the steel industry [8]. Due to Germany's dependence on the import of metals, it is essential to discover new and own potential ore resources/deposits since economic and political problems in supplying countries may cause supply risks for certain commodities. A typical example is the global dependency on cobalt from DR Congo, which has $64 \%$ of the world's primary cobalt production [10]. The mining of polymetallic nodules as well as Co-rich ferromanganese crusts from the deep seabed could be an opportunity to lower this dependency.

Currently there are not only 15 licenses for the exploration of Mn nodules granted by the International Seabed Authority, but there also are serious efforts to develop mining technology by both private companies and state-owned organizations worldwide. Since 2006, Germany has held a license area of $75,000 \mathrm{~km}^{2}$ for Mn nodule exploration within the Clarion and Clipperton Zone (CCZ) of the Pacific Ocean [11].

The Federal Institute for Geosciences and Natural Resources has the assignment to investigate this area with regard to nodule occurrence, distribution, coverage, and chemical composition. High nodule abundance $\left(>10 \mathrm{~kg} / \mathrm{m}^{2}\right)$ and a high concentration of economically important metals $(\mathrm{Ni}+\mathrm{Cu}+\mathrm{Co}$ up to $3 \mathrm{wt} \%$ ) [11,12] could be proven in several sub-regions of the German license area, which makes them prospects for future mining $[13,14]$.

In several research studies such as BlueMining, mining concepts and mining equipment for further deep sea mining have been developed [15]. Consequently, the next step is to create a valuable extraction method for economically interesting metals such as $\mathrm{Ni}, \mathrm{Cu}, \mathrm{Co}$, and $\mathrm{Mo}$. The technology of processing of nodules is of particular importance for the assessment of the economic viability of deep-sea mining since it covers about $50 \%$ of the investment costs [16].

The metallurgical treatment of polymetallic nodules to extract individual metals is very complex because of the nodule composition and internal structures. In general, nodules are composed of different Mn-oxides and Fe-(oxy)hydroxides with small particle sizes $(<0.01 \mu \mathrm{m})$. Moreover, the particles are intergrown with each other on a very fine scale through the whole nodule $(\mathrm{nm}-\mu \mathrm{m})$ [17-19], which makes the metallurgical treatment challenging and conventional beneficiation methods inapplicable.

In general, nodules consist of individual growth structures of different genesis, alternating with each other around a nucleus (e.g., basaltic rock fragments, shark teeth, sediment) [1]. On the one hand, hydrogenetic growth structures occur that form due to metal precipitation from oxygen-rich water (near bottom water/sediment pore water). These growth structures contain on average $23 \mathrm{wt} \%$ $\mathrm{Mn}, \sim 14$ wt \% Fe, $\sim 0.42$ wt \% Ni, $\sim 0.33$ wt \% Cu, $\sim 0.27$ wt \% Co, and $\sim 0.04$ wt \% Mo (e.g., [9]). Mineralogically hydrogenetic layer growth structures consist of Mn-oxides such as vernadite $\left(\delta-\mathrm{MnO}_{2}\right.$ $\left.\left.\mathrm{Mn}^{4+}, \mathrm{Fe}^{3+}, \mathrm{Ca}, \mathrm{Na}\right)(\mathrm{O}, \mathrm{OH})_{2} \cdot \mathrm{n}\left(\mathrm{H}_{2} \mathrm{O}\right)\right)$. This Mn-oxide consists of $\left[\mathrm{MnO}_{6}\right]$ octahedra forming mono sheets, which are epitaxially intergrown with an amorphous $\mathrm{FeOOH}$ phase [20].

On the other hand, diagenetic layer growth structures occur due to metal precipitation from suboxic waters (near bottom water/pore water). These growth structures have higher concentrations of $\mathrm{Mn}(\sim 45 \mathrm{wt} \%), \mathrm{Ni}(1.4 \mathrm{wt} \%), \mathrm{Cu}(1.4 \mathrm{wt} \%)$, and Mo ( 0.08) but lower contents of Fe (0.06-4 wt \%) as well as $\mathrm{Co}(0.05 \mathrm{wt} \%)$ (e.g., [9]) compared to hydrogenetic growth structures. Diagenetic growth 
structures consist of 7 and $10 \AA$ phyllomanganates. These Mn-oxides consist of $\left[\mathrm{MnO}_{6}\right]$ octahedral sheets that are stacked with a defined separation from each other in the crystallographic $c$ direction and hydrated cations in interlayers between them (e.g., $\mathrm{Mg}, \mathrm{K}, \mathrm{Na}, \mathrm{Ca})[18,21,22]$. Due to structural vacancies within the octahedral sheets and/or because of the substitution of $\mathrm{Mn}^{3+}$ for $\mathrm{Mn}^{4+}$ within the $\left[\mathrm{MnO}_{6}\right]$ octahedral sheets, all three manganese phases have a negative layer charge deficit, which can be compensated by the incorporation of metals into the vacancies or by the substitution of manganese of lower valence [21,23-25].

Metals such as $\mathrm{Ni}, \mathrm{Cu}, \mathrm{Co}$, and Mo are preferentially incorporated as inner-sphere complexes within the octahedra of the sheets [25-29]. Therefore, those metals are structurally incorporated within the Mn phases, which makes the extraction more difficult.

In addition to the main manganese and iron (oxy)hydroxides, sediment always occurs within nodules and is incorporated within the cracks and pores (porosity: up to 60\%) of those nodules $[5,9,30]$. Typical accessory minerals are feldspar, zeolites (phillipsite), illite, kaolinite, barite, quartz, and halite [19].

Due to the small particle size, the heterogeneous distribution of the metals in the nodules, and the fact that the different $\mathrm{Mn}-\mathrm{Fe}$ (oxy)hydroxides are epitaxially intergrown with each other, a pre-concentration via mineral processing methods like density separation, flotation, and magnetic separation to produce metal-rich concentrates appears impossible (e.g., [31]).

During the 1970s and 1980s, different studies were conducted to extract metals from polymetallic nodules [32,33], but most of them were unsuccessful. Recently, different approaches were used to extract metals from polymetallic nodules $[34,35]$. The metals have to be extracted in a cost- and energy-efficient way. Conventional metallurgical processes for polymetallic nodules are based on the treatment of $100 \%$ of the nodules mass to beneficiate $3 \%$ of valuable metals out of the mass stream. This means a significant amount of thermal energy or chemicals is needed to separate metals from waste.

Therefore, Leonhardt [31] conducted a selective reduction procedure using different reagents such as coke and sulfur to produce metal-rich particles. The study of Leonhardt [31] is the basis for this work. Here, we present high metal enrichment in newly formed, individually separated particles by thermal pre-treatment of the polymetallic nodules in order to enable further conventional mechanical separation of those particles from the remaining nodule matrix. The aims of the study are to investigate: (1) the metallization degree of the economically interesting metals $(\mathrm{Ni}, \mathrm{Cu}, \mathrm{Co}$, and Mo); (2) the characteristics of the metal-rich particles; and (3) the grain size of the newly formed metal-rich particles.

\section{Materials and Methods}

\subsection{Polymetallic Nodules}

Polymetallic nodule samples that were used for this study represent an average of nodules occurring in the eastern German license area within the CCZ.

For the study nodules of different size and chemical composition were chosen for further heating experiments. Nodule sizes range from $\sim 3 \mathrm{~cm}$ to $\sim 10 \mathrm{~cm}$ in diameter (Figure 1). In general, nodules from the German license area are mixed-type nodules consisting of different proportions of hydrogenetic and diagenetic growth structures $[5,7,9]$. Small nodules preferentially contain higher proportions of hydrogenetic material, which means higher Fe (14 wt \%) and $\mathrm{Co}(0.3 \mathrm{wt} \%)$ concentrations compared to medium and large nodules (Fe: $6 \mathrm{wt} \%$; Co: $0.15 \mathrm{wt} \%$ ). Those nodules have higher proportions of diagenetic material and therefore higher $\mathrm{Mn}(33 \mathrm{wt} \%), \mathrm{Ni}(1.4 \mathrm{wt} \%)$ and $\mathrm{Cu}(1.2 \mathrm{wt} \%)$ concentrations. 


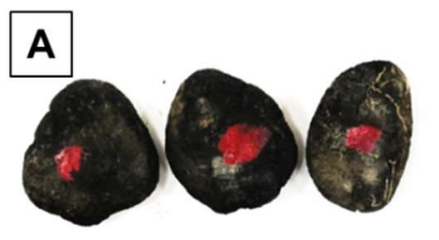

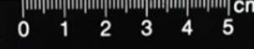

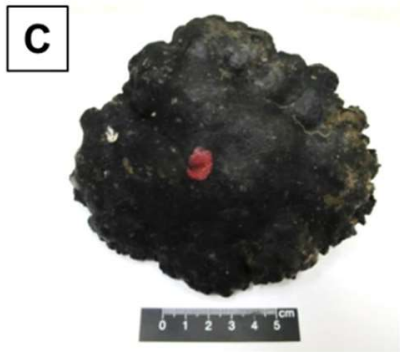

B
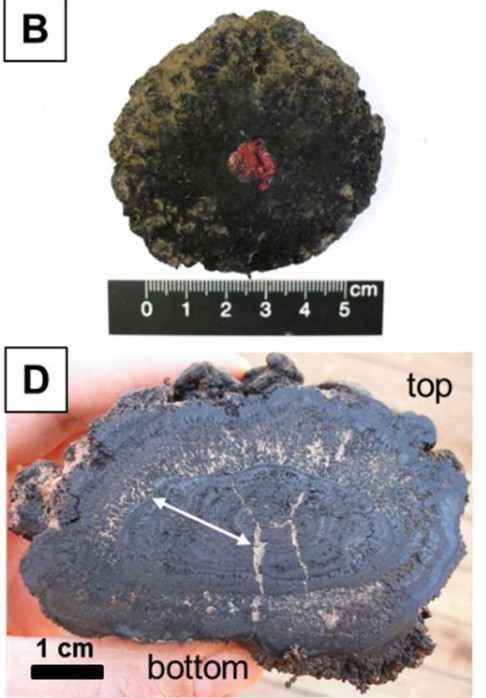

Figure 1. (A-C) Small to big nodules $(3->8 \mathrm{~cm})$ with different proportions of hydrogenetic and diagenetic layer growth structures. Small nodules (A) are spherical to discoidal with smooth surfaces; Medium to large nodules $(\mathbf{B}, \mathbf{C})$ have a higher proportion of diagenetic material than the small ones. Those nodules are discoidal to ellipsoidal with a botryoidal rim, which indicates the interface between the upper (smooth) surface, which was in contact with the near bottom water, and the lower (rough) side, which was embedded within the sediment. The red dot marks the nodule's upper surface during sampling. (D) Cross section of a typical large nodule. Dense and porous growth structures alternate with each other through the whole nodule. Pores and cracks are filled with siliceous ooze (marked with white arrow) [5].

Figure 2 represents the individual, genetically different growth structures that are intergrown with each other on a very fine scale and the metal distribution through those structures.
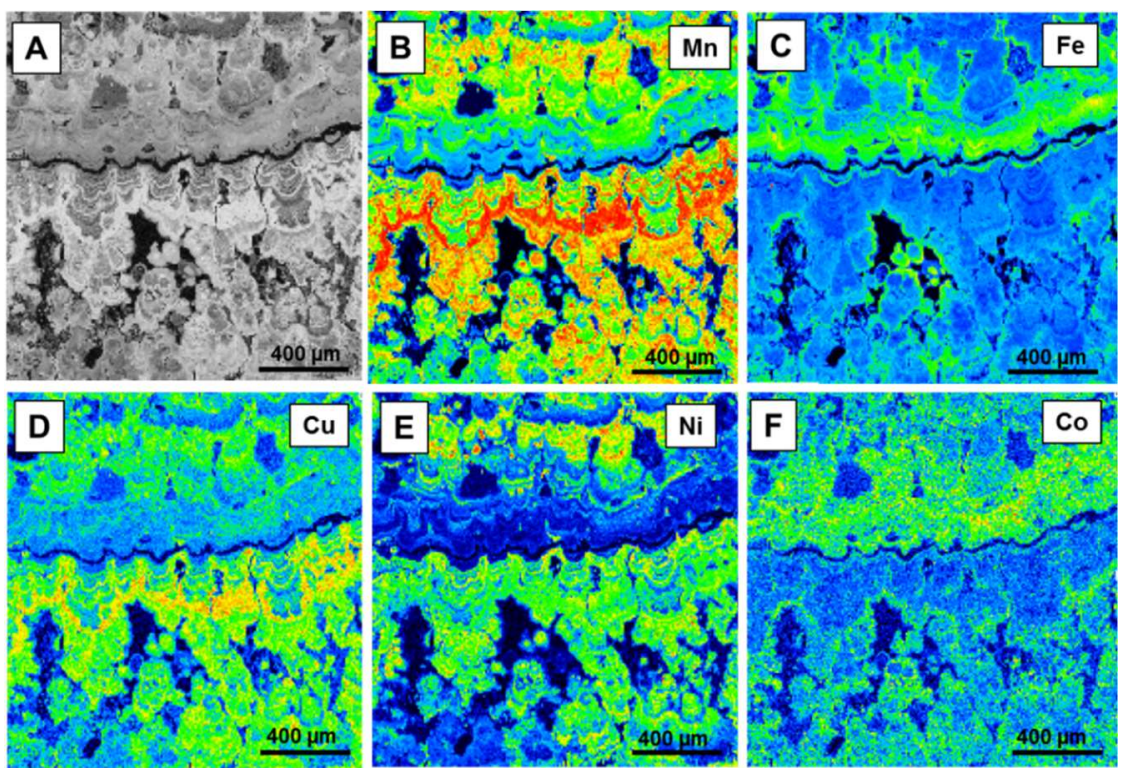

high content

low content

Figure 2. (A) Backscattered electron (BSE) image and (B-F) element distribution maps of $\mathrm{Mn}, \mathrm{Fe}, \mathrm{Ni}, \mathrm{Cu}$, and $\mathrm{Co}$ of growth structures of a Mn nodule from the CCZ. Genetically different growth structures as well as the different $\mathrm{Mn}$ and $\mathrm{Fe}$ (oxy)hydroxides are intergrown with each other on a very fine scale (nm- $\mu \mathrm{m})$. 


\subsection{Thermal Pre-Treatment of Polymetallic Nodules}

For thermal pre-treatment experiments, nodules were ground down to $\sim 200 \mu \mathrm{m}$ and mixed with different reactants (same particle size) such as coke, quartz, and elementary sulfur in different proportions (Table 2). Coke and sulfur were already used in experiments in the 1970s [31] and showed positive results. According to Beck and Messner [33], quartz increases the viscosity [36] and the acidity as well as decreases the melting point in a metallurgical system. So, for the thermal treatment of polymetallic nodules this could decrease the required energy input. To investigate the influence of quartz, it was added to samples P5 and P6. To investigate the influence of the grain size, one sample was ground to $\leq 315 \mu \mathrm{m}$ and the other sample was ground down to a particle size of $\leq 45 \mu \mathrm{m}$. The reactants added are the same in both samples (Table 2). Nodule material (1-1.5 kg) and reactants were heated within a rotary kiln at temperatures between 1050 and $1100{ }^{\circ} \mathrm{C}$ for $2 \mathrm{~h}$. The experiments were conducted under reduced conditions (inert gas atmosphere). Afterwards the kiln was turned off and the samples cooled down for $10 \mathrm{~h}$. Since nodules and reactants were added as powders, providing large surfaces, and due to the rotary movement during the reaction period, almost complete mixing and reaction of nodule and reactant particles could be guaranteed.

Table 2. Composition of the sample powder experiments.

\begin{tabular}{cccc}
\hline Samples & Coke [\%] & Quartz [\%] & Sulfur [\%] \\
\hline P1 $(<200 \mu \mathrm{m})$ & 8 & 0 & 0 \\
P2 $(<200 \mu \mathrm{m})$ & 9 & 0 & 0 \\
P3 $(<200 \mu \mathrm{m})$ & 12 & 0 & 1.2 \\
P4 $(<200 \mu \mathrm{m})$ & 14 & 0 & 1.2 \\
P5 $(<315 \mu \mathrm{m})$ & 20 & 10 & 2 \\
P6 $(<45 \mu \mathrm{m})$ & 20 & 10 & 2 \\
\hline
\end{tabular}

\subsection{Scanning Electron Microscopy (SEM) and Mineral Liberation Analysis (MLA)}

For the investigation of the thermally pre-treated samples, SEM analyses were conducted using a Quanta 650 FEG SEM (FEI/Thermo Fisher Scientific, Eindhoven, The Netherlands) combined with MLA software version 3.0 (FEI/Thermo Fisher Scientific) to characterize and quantify all particles in the samples. The SEM is equipped with two Bruker energy-dispersive X-ray detectors (XFlash Detector 5030, Silicon Drift Detector; Bruker Nano) (Bruker Corporation, Billerica, MA, USA) for semi-quantitative element analysis without standardization.

For further investigations of each individual experiment (P1-P6), thin sections were prepared.

The mineralogical composition of the particles was quantitatively determined using SEM/mineral liberation analysis techniques (SEM/MLA-XBSE (X-ray backscatter electron) [37,38]). In each section, the chemical composition was identified using energy-dispersive X-ray spectrometry (EDS) combined with backscattered electron (BSE) imaging. In a first step, BSE images are collected, and based on the grey values of the particles in the images, an automated function performs de-agglomeration and definition of individual particles. Afterwards, all distinct grains and their boundaries are accurately defined. X-ray analyses are performed using a point procedure. Every particle with a different grey value will be measured with EDS. The measured mineral spectra will be compared with spectra of pre-defined mineral standards to determine the mineral identity for each grain.

Numerous parameters like modal mineralogy and grain size distribution (of each individual mineral) can be deduced from the collected data.

\subsection{Investigation of the Metallization Degree}

The goal of heating experiments was to transfer valuable elements such as $\mathrm{Ni}, \mathrm{Cu}, \mathrm{Co}$, and $\mathrm{Mo}$, which are incorporated in the crystal structure of Mn-oxides, into a separated metallic form. Before nodules were heated they were analyzed for their general geochemical composition using the $X$-ray fluorescence method in the laboratory of BGR. 
To investigate the amount of those elements in a metallic form, the metallization degree has been investigated by the HuK Umweltlabor $\mathrm{GmbH}$. To investigate the metallization degree, experimental samples were treated according to the Bromine/Methanol-Extraction method developed by Füchtjohann [39]. With this approach all of the metallic phases (except vanadium) were dissolved and the solutions were analyzed via Inductively Coupled Plasma-Mass Spectrometry (ICP-MS) to investigate the individual metal proportion in the different samples [39].

\subsection{Electron Probe Microanalysis (EPMA)}

Electron probe microanalyses (EMP: JEOL JXA-8530F, JEOL, Akishima, Tokyo, Japan) were conducted to investigate the chemical composition of the newly formed metal-rich particles of sample P3 and P4, which have the highest metallization degrees. Analyses were done on polished thin sections with $20 \mathrm{kV}$ accelerating voltage and $40 \mathrm{nA}$ beam current. The particles were measured with a focused $(\sim 1 \mu \mathrm{m})$ beam. The counting times for the analyzed elements were $10 \mathrm{~s}$ for $\mathrm{Mn}$ and $\mathrm{Fe}, 20 \mathrm{~s}$ for $\mathrm{Ni}$ and $\mathrm{Cu}, 30 \mathrm{~s}$ for $\mathrm{V}, \mathrm{Co}$ and $\mathrm{Zn}, 90 \mathrm{~s}$ for $\mathrm{Mo}$, and $20 \mathrm{~s}$ for $\mathrm{S}$. Manganese metal (Mn), pyrrhotite $(\mathrm{Fe}, \mathrm{S})$, cobalt metal $(\mathrm{Co})$, pentlandite $(\mathrm{Ni})$, chalcopyrite $(\mathrm{Cu})$, sphalerite $(\mathrm{Zn})$, molybdenite $(\mathrm{Mo})$, and vanadium metal $(\mathrm{V})$ were used as standards (BGR standards).

\section{Results}

\subsection{Metallization Degree}

Table 3 and Figure 3 show the metallization degree of samples after the individual heating experiments. Regarding the different metals, $\mathrm{Cu}(69-82 \%)$ is most enriched in the metallic phase within all samples followed by Mo (48-75\%), Ni (54-73\%) and Co (51-73\%). Additionally, Fe and Mn were transformed from the oxic phase into the metallic phase, with more Fe (29-95\%) being transformed than Mn (3-17\%; Table 3).

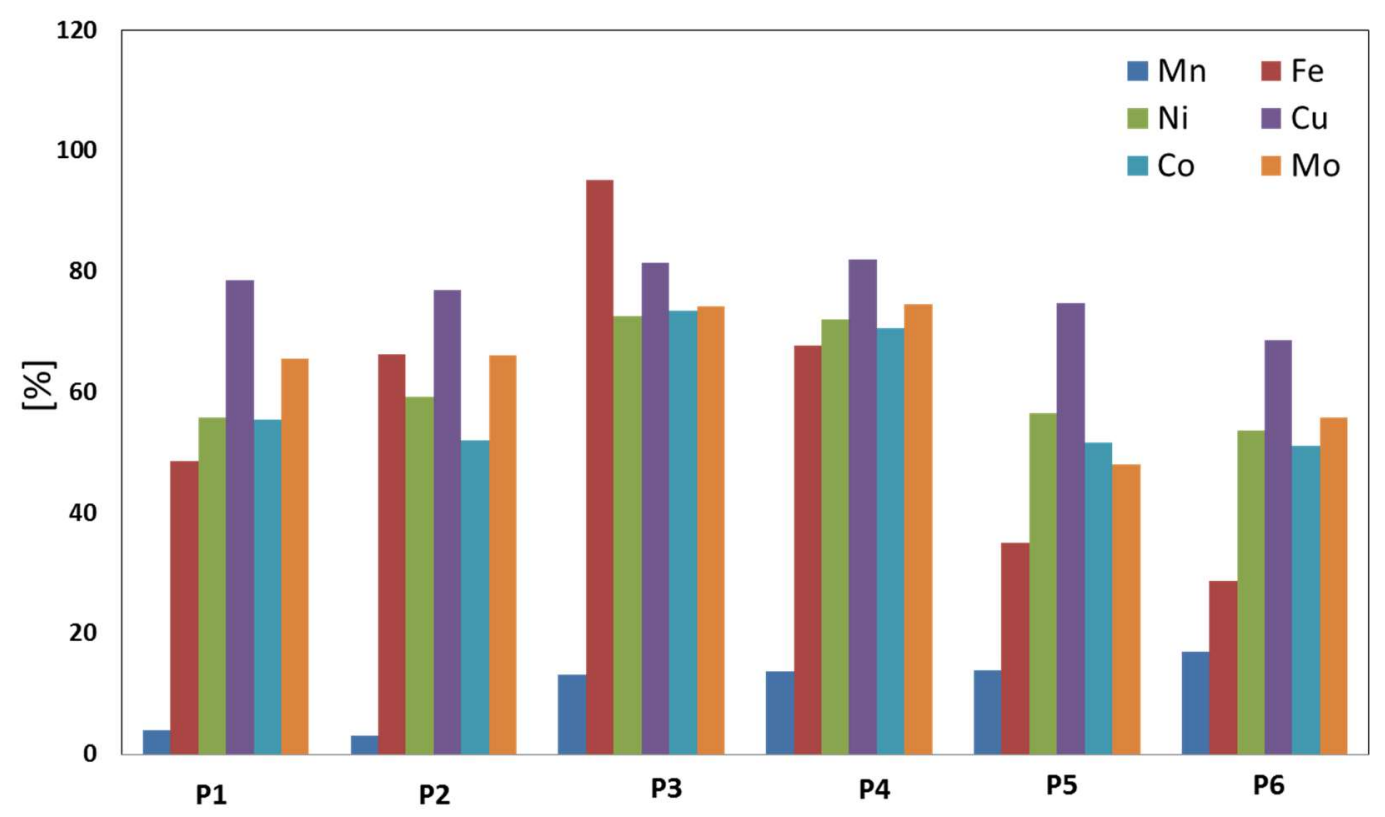

Figure 3. Metallization degrees of sample P1-P6. Samples P3 and P4 have the highest metallization degrees. 
Table 3. Metallization degree of samples P1-P6.

\begin{tabular}{ccccccc}
\hline Metallization Degree [\%] & P1 & P2 & P3 & P4 & P5 & P6 \\
\hline Mn & 3.99 & 3.05 & 13.2 & 13.8 & 14.0 & 17.1 \\
$\mathrm{Fe}$ & 48.5 & 66.3 & 95.2 & 67.8 & 35.0 & 28.8 \\
$\mathrm{Ni}$ & 55.8 & 59.2 & 72.7 & 72.1 & 56.6 & 53.7 \\
$\mathrm{Cu}$ & 78.5 & 77.0 & 81.4 & 82.0 & 74.8 & 68.6 \\
$\mathrm{Co}$ & 55.6 & 52.1 & 73.4 & 70.6 & 51.6 & 51.2 \\
$\mathrm{Mo}$ & 65.7 & 66.1 & 74.2 & 74.6 & 48.0 & 55.8 \\
\hline
\end{tabular}

According to these analyses, experiments $\mathrm{P} 3$ and $\mathrm{P} 4$ have the highest metallization degrees. Within these samples, $70-80 \%$ of the target elements $(\mathrm{Ni}, \mathrm{Co}, \mathrm{Cu}, \mathrm{Mo}$, and $\mathrm{Fe}$ ) were transferred from the oxide phase into a metallic phase. However, the amount of $\mathrm{Fe}$ within the metallic phase is also high $(68 \%$ and $95 \%)$ in experiment P3 and P4, but only up to $14 \%$ of Mn transforms from the oxide into the metallic phase. Samples P5 and P6 represent the lowest metallization degrees (Figure 3).

\subsection{High-Resolution Investigations of the Pre-Treated Material (SEM + MLA)}

Investigations of the pre-treated experiments (P1-P6) using SEM showed that the internal structures of the nodules have been partly changed (Figure $4 \mathrm{~A}$ ). That means that there are parts of the nodules that still show the typical layered growth structures of the original nodules, such as is visible in Figure 4B. However, in all samples bright spheroidal to elongated particles occur with sizes between $<1 \mu \mathrm{m}$ to $20 \mu \mathrm{m}$ (Figure $4 \mathrm{~A}$ ). Those particles occur predominantly within the transformed nodule fragments. Only a few very small $(<<1 \mu \mathrm{m})$ bright particles can be found within the nodule fragments that have kept their original layered growth structures (Figure 4B). It should be noted that these bright spots preferentially occur in areas of diagenetic growth layers (metal-rich layers) and have not been found in the hydrogenetic layers (Figure 4B).
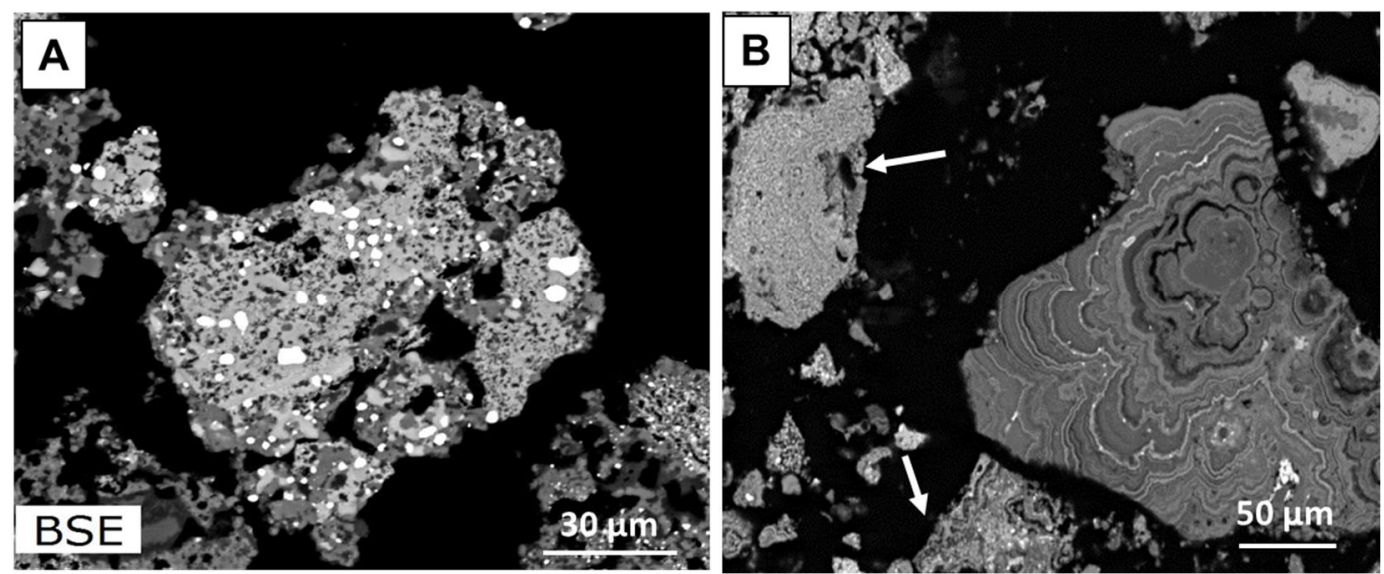

Figure 4. (A) Backscattered electron (BSE) image of a transformed nodule fragment of sample P3 (element mappings in Figure 5). (B) BSE image of a non-transformed nodule fragment of sample P1. Individual growth structures can still be recognized. Around the original fragment transformed fragments can also be recognized (marked with an arrow).

EDS analyses of these bright particles in all samples (P1-P6) show that they are enriched in metals such as $\mathrm{Cu}(5-10 \mathrm{wt} \%), \mathrm{Ni}(10-16 \mathrm{wt} \%), \mathrm{Fe}(\sim 50-60 \mathrm{wt} \%)$, and some Mn (5-10 wt \%). The concentration of those metals differs between the individual samples as well as within each sample. Furthermore, there are bright spheroidal metal-rich particles, which stick to coke particles in all samples. Those particles preferentially show much higher $\mathrm{Cu}$ concentrations up to $70 \mathrm{wt} \%$ and $\mathrm{Mn}, \mathrm{Ni}$, and Fe occur in minor amounts (for detailed measurements see EPMA analyses in Section 3.3). For the interpretation 
using MLA software, all bright particles were combined into one metal-bearing phase independent of the concentration of the metals and assigned to one mineral phase called the Fe-Me-phase.
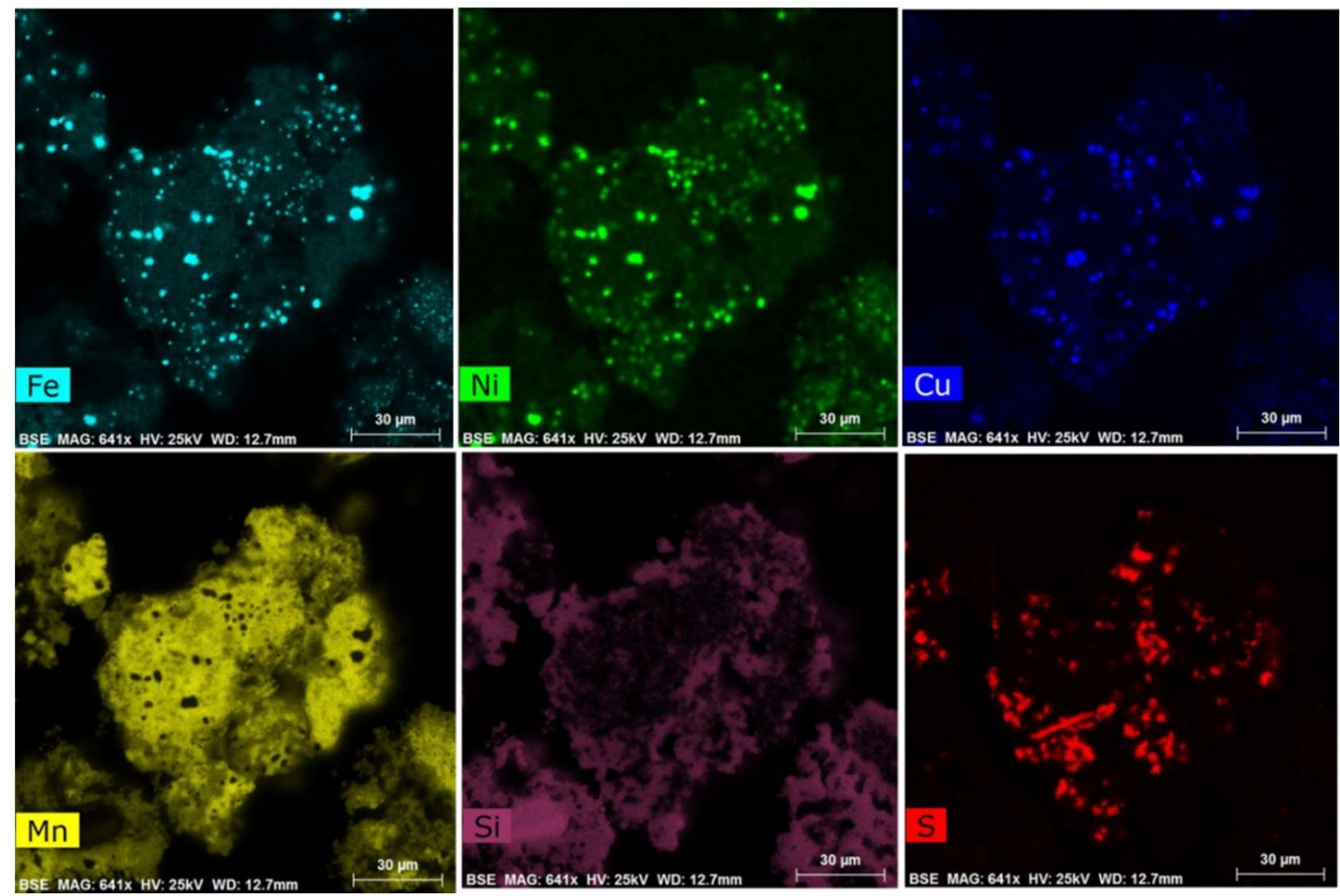

Figure 5. Element maps of a transformed nodule fragment of sample P3 (see BSE image in Figure $4 \mathrm{~A}$ ). $\mathrm{Fe}, \mathrm{Ni}$, and $\mathrm{Cu}$ are preferentially concentrated within the bright metal-bearing spots and are characteristic for the Fe-Me-phase. $\mathrm{Mn}, \mathrm{Si}$, and $\mathrm{S}$ maps display three different $\mathrm{Mn}$ phases in one fragment. Mn-rich areas without Si and S represent the Mn-oxide phase, Mn together with Si characterize Mn-silicates, and S-rich areas stand for the MnS phase. Metals like $\mathrm{Ni}, \mathrm{Cu}$, and $\mathrm{Co}$ are not highly enriched in these areas $(<1 \mathrm{wt} \%)$.

In addition to these metal-rich particles, samples P3-P6 contain Mn-sulfides, which also incorporate low amounts of metals in different proportions ( $\mathrm{Ni}$ and $\mathrm{Cu}<1 \mathrm{wt} \%$; Figures 4 and 5 . These phases are assigned as MnS phase. The MnS phases show xenomorphic structures that are intergrown with the remaining slag consisting of Mn-oxides and Mn-silicates (Figure 4A). In this study it was important to investigate the distribution and amount of the general metal-bearing phases.

Element mappings of individual fragments (Figure 4A) were conducted to get an idea of the distribution of the different phases (Figure 5). Figure 5 demonstrates that $\mathrm{Fe}, \mathrm{Ni}$, and $\mathrm{Cu}$ are concentrated in the bright spheroidal spots visible in Figure 4A. The light grey matrix in which the metal-rich particles are embedded consists of a mixture of the MnS phase, Mn-oxides, and Mn-silicates (Figures 4 and 5).

Using MLA software, the two metal-bearing phases, Fe-Me-phase and MnS phase, were investigated. Analyses of the data indicate that the MnS phases occur in higher proportions than the Fe-Me-phases (Figure 6). For the precise chemical composition of both metal-bearing phases, EPMA analyses were conducted (see Section 3.3, Table 4). 


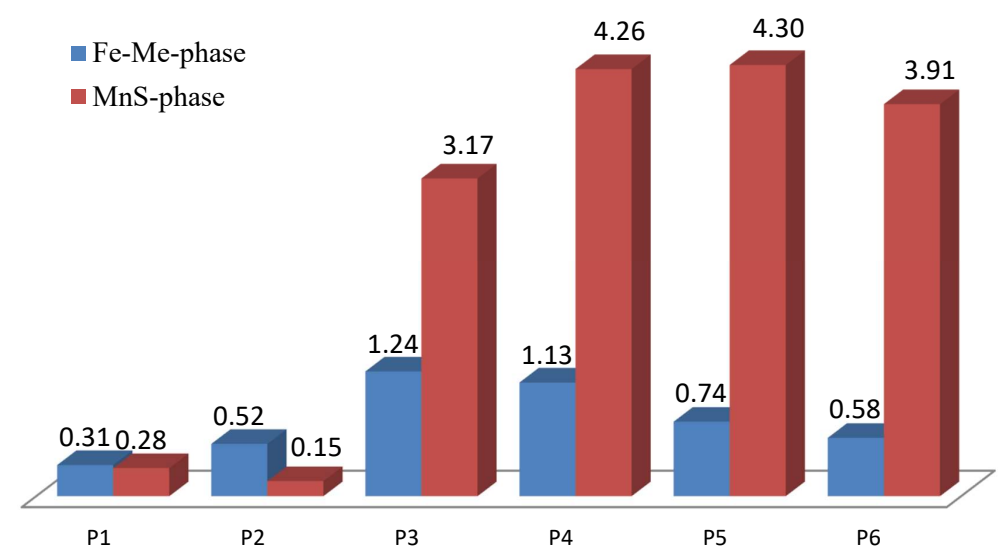

Figure 6. Fractions in \% of the two main metal-bearing phases in samples P1-P6, determined with MLA software.

Table 4. Chemical composition of metal-bearing phases of samples P3 and P4. All contents are given in wt \%.

\begin{tabular}{|c|c|c|c|c|c|c|c|c|c|c|}
\hline & & $S$ & $\mathbf{V}$ & Mn & $\mathrm{Fe}$ & Co & $\mathrm{Ni}$ & $\mathrm{Cu}$ & Zn & Mo \\
\hline \multirow{5}{*}{ P3 } & average (Fe-Me-phase) & 0.03 & 0.02 & 6.53 & 58.2 & 3.34 & 18.06 & 11.84 & 0.00 & 0.34 \\
\hline & stabw & 0.05 & 0.02 & 3.41 & 8.75 & 3.89 & 5.40 & 4.83 & u.d.l. & 0.16 \\
\hline & median & 0.03 & 0.02 & 6.49 & 56.3 & 2.56 & 16.3 & 11.22 & u.d.l. & 0.32 \\
\hline & $\min$ & 0.00 & 0.00 & 1.13 & 43.7 & 1.21 & 8.05 & 3.37 & u.d.l. & 0.09 \\
\hline & $\max$ & 0.16 & 0.08 & 11.0 & 77.7 & 18.3 & 30.8 & 25.3 & u.d.l. & 0.65 \\
\hline \multirow{5}{*}{ P4 } & average (Fe-Me-phase) & 0.04 & 0.02 & 4.78 & 67.1 & 1.86 & 14.1 & 9.25 & u.d.l. & 0.38 \\
\hline & stabw & 0.06 & 0.01 & 1.54 & 7.41 & 0.33 & 4.81 & 2.41 & u.d.l. & 0.12 \\
\hline & median & 0.04 & 0.03 & 4.93 & 65.9 & 1.87 & 14.7 & 9.08 & u.d.l. & 0.36 \\
\hline & $\min$ & 0.00 & 0.00 & 2.38 & 54.1 & 1.21 & 4.43 & 5.17 & u.d.l. & 0.23 \\
\hline & $\max$ & 0.23 & 0.04 & 6.89 & 80.8 & 2.44 & 23.9 & 14.5 & u.d.l. & 0.71 \\
\hline \multirow{5}{*}{ P3 } & average (MnS-phase) & 36.1 & 0.01 & 61.5 & 0.27 & 0.01 & 0.03 & 0.11 & u.d.l. & 0.00 \\
\hline & stabw & 2.06 & 0.01 & 0.79 & 0.21 & 0.02 & 0.02 & 0.07 & u.d.l. & 0.01 \\
\hline & median & 36.9 & 0.01 & 61.6 & 0.19 & 0.00 & 0.03 & 0.09 & u.d.l. & 0.00 \\
\hline & $\min$ & 30.9 & 0.00 & 59.5 & 0.11 & 0.00 & 0.00 & 0.03 & u.d.l. & 0.00 \\
\hline & $\max$ & 38.1 & 0.03 & 63.0 & 0.75 & 0.08 & 0.05 & 0.21 & u.d.l. & 0.03 \\
\hline \multirow{5}{*}{$\mathrm{P} 4$} & average (MnS-phase) & 34.7 & 0.01 & 59.8 & 0.31 & 0.00 & 0.06 & 0.12 & u.d.l. & 0.00 \\
\hline & stabw & 1.18 & 0.01 & 1.70 & 0.18 & 0.01 & 0.04 & 0.05 & u.d.l. & 0.01 \\
\hline & median & 35.4 & 0.01 & 60.1 & 0.21 & 0.00 & 0.04 & 0.09 & u.d.l. & 0.00 \\
\hline & $\min$ & 32.7 & 0.00 & 57.6 & 0.19 & 0.00 & 0.03 & 0.08 & u.d.l. & 0.00 \\
\hline & $\max$ & 35.5 & 0.02 & 61.5 & 0.63 & 0.02 & 0.12 & 0.20 & u.d.l. & 0.01 \\
\hline \multirow{5}{*}{ P4 } & average ( $\mathrm{Cu}$ on cokes) & 0.07 & 0.00 & 1.83 & 0.72 & 0.02 & 0.43 & 91.9 & 2.23 & 0.02 \\
\hline & stabw & 0.10 & 0.00 & 0.65 & 0.03 & 0.02 & 0.08 & 0.75 & 0.14 & 0.00 \\
\hline & median & 0.00 & 0.00 & 2.03 & 0.73 & 0.02 & 0.41 & 92.2 & 2.32 & 0.02 \\
\hline & $\min$ & 0.00 & 0.00 & 0.95 & 0.68 & 0.00 & 0.34 & 90.9 & 2.03 & 0.01 \\
\hline & $\max$ & 0.20 & 0.00 & 2.52 & 0.75 & 0.04 & 0.54 & 92.7 & 2.34 & 0.02 \\
\hline P3 & average (Cu on cokes) & $0-0.04$ & 0.00 & $0.6-3.5$ & $1.7-3.5$ & $0.02-0.2$ & $1.8-3.7$ & $87-93$ & u.d.l. & $0-0.02$ \\
\hline \multirow{5}{*}{ P3 } & average (Cu-rich) & 0.07 & 0.00 & 10.4 & 4.56 & 0.94 & 7.58 & 75.7 & u.d.l. & 0.01 \\
\hline & stabw & 0.05 & 0.00 & 0.56 & 1.64 & 1.61 & 0.82 & 2.72 & u.d.l. & 0.01 \\
\hline & median & 0.06 & 0.00 & 10.4 & 4.19 & 0.23 & 7.37 & 76.3 & u.d.l. & 0.01 \\
\hline & $\min$ & 0.00 & 0.00 & 9.72 & 2.80 & 0.12 & 6.74 & 71.5 & u.d.l. & 0.00 \\
\hline & $\max$ & 0.14 & 0.00 & 11.5 & 7.27 & 4.54 & 9.02 & 78.8 & u.d.l. & 0.03 \\
\hline \multirow{5}{*}{ P3 } & average (Co-rich) & 0.14 & 0.00 & 6.67 & 6.50 & 73.7 & 8.13 & 5.88 & u.d.l. & 0.15 \\
\hline & stabw & 0.02 & 0.00 & 1.14 & 2.28 & 5.57 & 3.45 & 1.18 & u.d.l. & 0.11 \\
\hline & median & 0.14 & 0.00 & 6.35 & 5.27 & 75.0 & 8.61 & 5.36 & u.d.l. & 0.15 \\
\hline & $\min$ & 0.11 & 0.00 & 5.29 & 4.14 & 59.5 & 3.54 & 4.92 & u.d.l. & 0.04 \\
\hline & $\max$ & 0.17 & 0.01 & 8.81 & 10.3 & 78.4 & 14.8 & 8.68 & u.d.l. & 0.27 \\
\hline P3 & Fe on cokes & 0.04 & 0.00 & 0.20 & 93.7 & 0.04 & 0.96 & 1.53 & u.d.l. & 0.02 \\
\hline P3 & Co-Fe phase & $0.09-0.11$ & $0.04-0.07$ & $9.2-10.6$ & $29-34$ & $37-38.5$ & $9.5-12.3$ & $9.02-9.60$ & u.d.l. & $0.30-0.50$ \\
\hline P3 & Fe-rich phase & 0.00 & 0.00 & 1.30 & $85-89$ & $1.2-1.4$ & $4.8-7.7$ & $2.5-3.0$ & u.d.1. & 0.08 \\
\hline
\end{tabular}




\subsection{Electron Probe Microanalysis}

Electron probe microanalyses of metal-bearing phases were conducted to check their detailed composition. Here we concentrate on samples P3 and P4 because both display the highest metallization degrees (see Section 3.1). Table 4 summarizes the chemical composition of a range of different particles that occur within the samples.

The bright particles of samples P3 and P4 show high chemical variability. These particles (Figure 7A-F) mainly consist of different amounts of Fe, Mn, Ni, Cu, and Co, as well as Mo (Table 4).
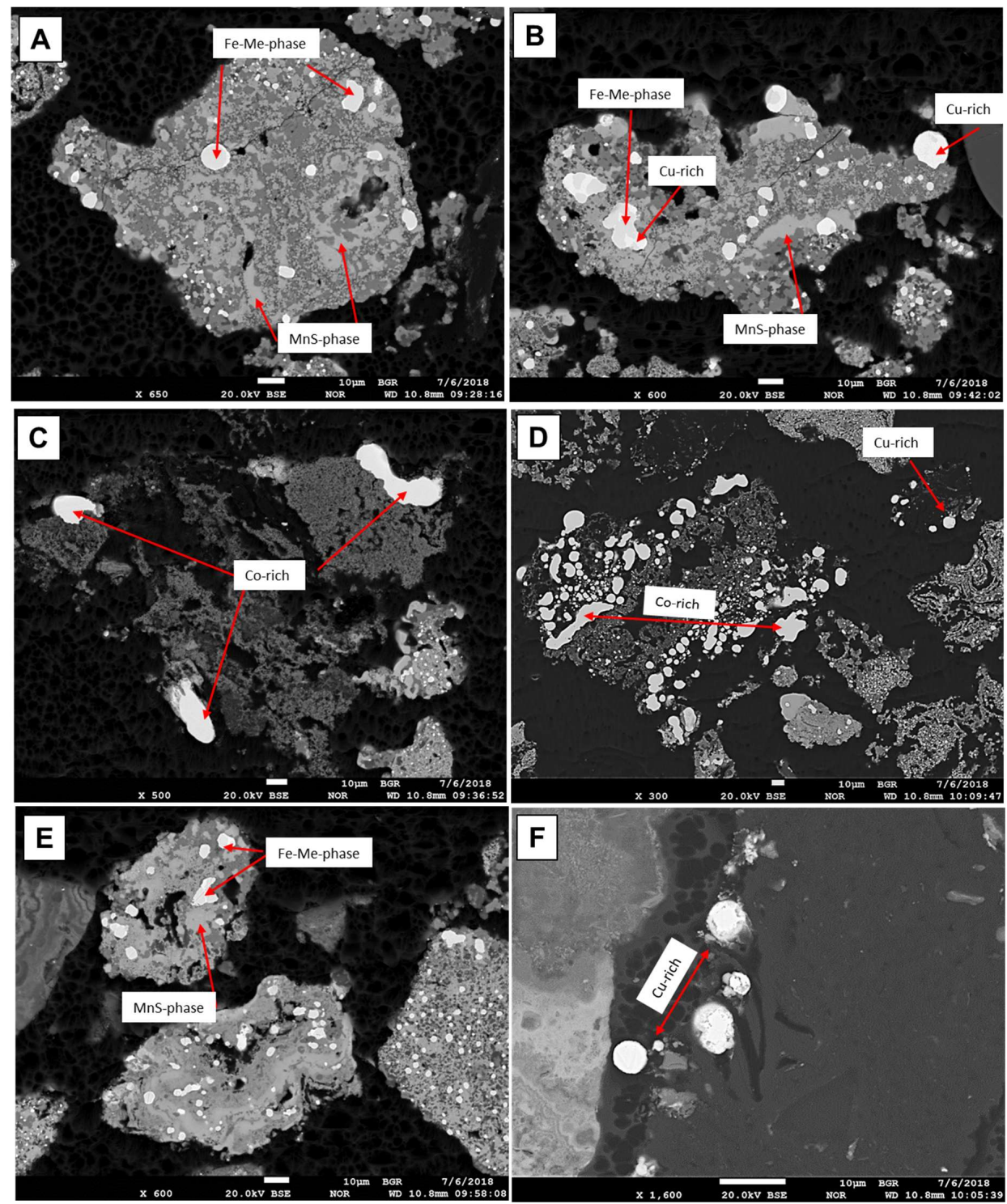

Figure 7. BSE images of different metal-bearing particles of samples P3 and P4, with bright particles representing the metal-bearing phases. They have a high variability of the incorporated economically interesting metals. (A,B) Bright particles are distributed within former nodule material, which is transformed, now consisting of Fe-Me-phase and MnS phase intermixed with Mn-oxides and Mn-silicates. (C-F) Metal-bearing particles that are preferentially enriched in $\mathrm{Cu}$ or $\mathrm{Co}$, located near coke particles.

The dominant particles in samples P3 and P4 consist of a mixture of Fe (44-81 wt \%), Ni (4-31 wt \%), Cu (3-25 wt \%), Co (1-18 wt \%), Mn (1-11 wt \%), and Mo (0.09-0.7 wt \%), called Fe-Me phase (Table 4, Figure 7). 
Furthermore, in both samples (P3 and $\mathrm{P} 4$ ) Cu-rich particles occur, which are predominantly stuck to coke particles (Figure 7). Those metal-bearing particles consist of $87-93 \mathrm{wt} \% \mathrm{Cu}$ and are depleted in all other metals (Table 4). Only the Cu-rich phase of sample P4 includes up to $2.3 \mathrm{wt} \% \mathrm{Zn}$. In all other metal-rich particles, $\mathrm{Zn}$ could not be detected.

Furthermore, sample P3 shows Co-rich particles with Co contents up to $78 \mathrm{wt} \%$, with minor amounts of all other target elements as well as some Mn and Fe. Additionally a Fe-bearing phase (Fe content up to $94 \mathrm{wt} \%$ ) occurred close to coke particles (Table 4). Moreover, it could be detected that almost all metal-rich particles display zonation or a heterogenetic structure. Analyses of those particles show that some parts are more $\mathrm{Cu}$-rich than others (Figure 7B). Detailed analyses of the MnS phase indicate very low contents of $\mathrm{Ni}+\mathrm{Cu}+\mathrm{Co}+\mathrm{Mo}(<0.5 \mathrm{wt} \%$; Table 4$)$.

In summary, the main metal-bearing phases are the spheroidal-elongated particles, which are interesting for further separation.

\subsection{The Grain Size Distribution of Metal-Bearing Particles}

The determination of the metal particle grain size is an important criterion for the determination of the success of the heating process. Figure 8 represents the grain size distribution of the main metal-bearing phase (Fe-Me-phase) of each sample (P1-P6). The analyses of the grain sizes were conducted using the D-values, determined by the MLA software. D-values are operating numbers, used in particle size distribution analysis. They describe percentages of particles of certain sizes. D90, e.g., indicates that $90 \%$ of the measured particles are smaller than the determined D90 grain size. Sample P1 shows the highest D 90 value with up to $12.71 \mu \mathrm{m}$. In this sample $10 \%$ of those particles are larger than $12.7 \mu \mathrm{m}$. Half of the Fe-Me-rich particles in sample P1 are even smaller than $3.85 \mu \mathrm{m}$ and $10 \%$ of the particles are smaller than $2.12 \mu \mathrm{m}$. Furthermore, sample P4 also shows high D90 values $(10.5 \mu \mathrm{m})$ and $50 \%$ of the particles are larger than $4 \mu \mathrm{m}$. In sample P3, 90\% of the metal-bearing particles are smaller than $7.9 \mu \mathrm{m}$, and in samples P6 and P2 90\% of the particles are $<6 \mu \mathrm{m}$ and $50 \%$ of the particles are below $<2.2 \mu \mathrm{m}$. P2 and P6 have the smallest Fe-Me particles.

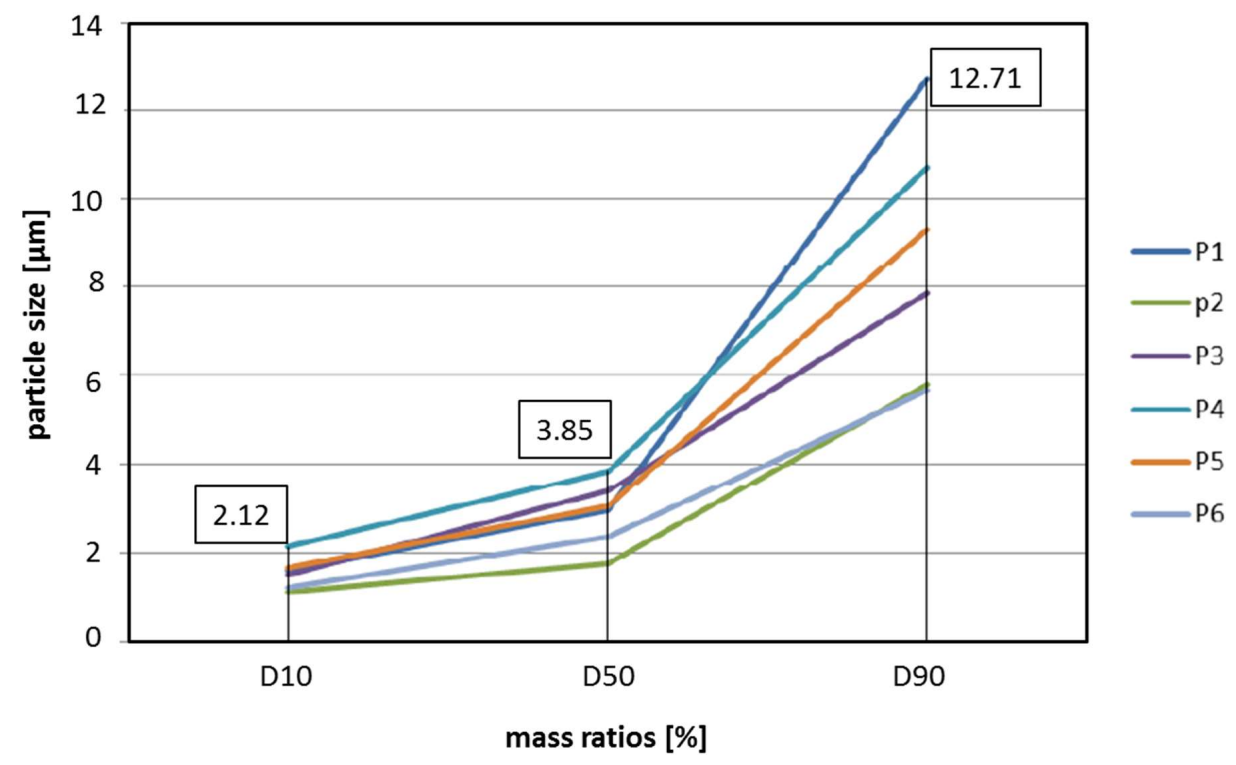

Figure 8. Grain size distribution of the Fe-Me phase of samples P1-P6.

\section{Discussion}

Polymetallic nodules from the German license area contain up to $3 \mathrm{wt} \% \mathrm{Ni}, \mathrm{Cu}, \mathrm{Co}$, and $\mathrm{Mo}$. These metals are distributed heterogeneously through the nodules and are preferentially incorporated in different Mn-oxide phases, which are furthermore intergrowth with $\mathrm{FeOOH}$ phases and detrital minerals. Therefore, the separation of pure metals from the Mn and Fe (oxy)hydroxide matrix using 
conventional beneficiation methods is impossible. Thus, a process has to be investigated that releases metals from the crystal structure of the minerals and enriches them within individual, newly formed particles. The aim is to make the mineral processing separation steps feasible to create metal-rich concentrates ready for further metallurgical treatment.

The present study demonstrates that a thermal pre-treatment of nodule material with different reactants (cokes, quartz, sulfur) in a rotary kiln $\left(1050-1100{ }^{\circ} \mathrm{C} / 2 \mathrm{~h}\right)$ mobilizes metals from the Mn-oxides of polymetallic nodules, similar to the investigation by Leonhardt [31]. During this thermal pre-treatment, individual metal-enriched particles form.

All samples (P1-P6) were mixed with different amounts of coke. Coke is used as a reducing agent for the metals to reduce them from their highest oxidation state into their elementary state [31]. Elementary sulfur in different proportions was added to samples P3-P6. In addition to coke, quartz was added to samples P5 and P6 to increase the viscosity [16] as well as the acidity of the feed material. Additionally, quartz decreases the melting point of the surrounding material [33] and therefore increases the energy efficiency of the whole process.

Sulfur was added to form sulfides, which bind metals. The mechanical treatment of sulfides is the state of the art in flotation processes and can be used for the separation of newly formed metal-rich sulfides [40]. Furthermore, Leonhardt [31] found that adding sulfur to the material resulted in larger metal particles, which is favorable for further metallurgical treatment.

According to Leonhardt [31], the reduction of Fe-oxides $\left(\mathrm{Fe}_{2} \mathrm{O}_{3}\right)$ into $\mathrm{Fe}_{3} \mathrm{O}_{4}$ starts at $303{ }^{\circ} \mathrm{C}$, the further reduction of $\mathrm{Fe}_{3} \mathrm{O}_{4}$ into $\mathrm{FeO}$ occurs at $577{ }^{\circ} \mathrm{C}$, and at $780{ }^{\circ} \mathrm{C} \mathrm{FeO}$ can be reduced to elementary iron.

The Mn phases (phyllomanganates; layered Mn-Oxide phases) start to transform mineralogically at $\geq 160{ }^{\circ} \mathrm{C}$ into tectomanganates (Mn-oxide phases with tunnel structures). During this mineralogical transformation, target elements such as $\mathrm{Ni}$ will be released from the phyllomanganate crystal structures $[29,41]$ into the slag. The target elements can be reduced by the coke into their elementary state and can form metal particles, together with elementary iron. During further heating, reduction of $\mathrm{MnO}_{2}$ to $\mathrm{Mn}_{2} \mathrm{O}_{3}$ occurs (at $\sim 750^{\circ} \mathrm{C}$ ) and reduction of $\mathrm{Mn}_{3} \mathrm{O}_{4}$ to $\mathrm{MnO}$ occurs at around $861{ }^{\circ} \mathrm{C}$ [42] . During this transformation metals can be released from the octahedra structures into the slag and be further reduced into elementary state and incorporated into the Fe-Ni metal particles. The heterogeneous composition of the metal particles may be due to different thermodynamics of the various elements involved. The slight enrichment of $\mathrm{Ni}$ over $\mathrm{Cu}$ and $\mathrm{Co}$ can be probably explained by the first mineralogical transformation of the Mn phases, which takes place at lower temperatures. During this reaction, up to $50 \%$ of $\mathrm{Ni}$ will be released from the structure [41]. In contrast, Co- and $\mathrm{Cu}$-rich particles will be released from the structure in a later phase of the Mn-oxide transformation at higher temperatures. During this transformation, pure individual particles can be formed. Complete reduction of Mn-oxides occurs at $\sim 1414{ }^{\circ} \mathrm{C}$ [31]. At temperatures above $1000{ }^{\circ} \mathrm{C}, \mathrm{Mn}$-silicates and probably MnS phases start to form [31]. The MnS phases do not contain high amounts of metals because the metals were released in a former transformation phase during which Fe-Me phases form.

In all samples fragments of the original nodule growth structures can be identified. A disadvantage of those pre-treatment experiments using powder is that the individual mixed particles only remain in contact with each other for a short time through the whole heating process in a rotary kiln and therefore the reaction time of the nodule sample with the reactants is probably too short to react completely. Because of that, not all of the metals are transformed into the metallic form and a part of the nodules remains in their original structural state. For this study, the reaction time in the rotary kiln was $2 \mathrm{~h}$. Longer reaction times should be tested; however, they will make the process more energy-intense and a balance between reaction time and energy consumption must be found.

Comparing the six experiments, P3 and P4 seem to be the most successful and promising because of their high metallization degrees (70-80\%). These samples show high contents of $\mathrm{Ni}, \mathrm{Cu}, \mathrm{Co}$, and Mo in the metallic phases but also a high proportion of Fe and Mn, which were transformed from the oxic into the metallic form. In contrast, samples P1 and P2 only reached a lower metallization degree 
$(50-78 \%)$ of $\mathrm{Ni}, \mathrm{Cu}, \mathrm{Co}$, and $\mathrm{Mo}$; on the other hand, lower concentrations of $\mathrm{Mn}$ and Fe occur within the metallic phases. The contents of Fe and $\mathrm{Mn}$ and their influence on further metallurgical treatments have to be investigated. Here the metallization degree of the target elements $(\mathrm{Ni}, \mathrm{Cu}, \mathrm{Co}$, and $\mathrm{Mo})$ is significant. In comparison to other extraction and beneficiation methods, a metallization degree of $80 \%$ is necessary to make the process valuable.

Aside from the degree of metallization of the target elements, the success and applicability of this beneficiation process also depends on the size of the newly formed particles.

Most of the target metals have been enriched in the Fe-Me-phase, which is distributed all over all samples but most enriched in samples P3 and P4. The largest particles occur in sample P1, but the majority of the particles are still very small $(50 \%<4 \mu \mathrm{m})$. In contrast, sample P4 represents relatively large metal-rich particles; here the size classes are more homogeneously distributed and almost $50 \%$ of the particles are larger than $4 \mu \mathrm{m}$. Adding sulfur to the mixture also results in larger particles that are more homogeneously distributed. However, the higher content of sulfur seems to lead to higher contents of $\mathrm{Fe}$ in the metallic phase. Moreover, the addition of too much coke and sulfur lowers the metal yield independent of the former material particle size [31].

The particle size, together with the high metallization degree of sample P4, indicates that the experimental setup of $\mathrm{P} 4$ leads to the most valuable results.

However, the particle sizes of the formed metal-bearing particles in all samples are generally relatively small $(\mathrm{D} 90<12.71 \mu \mathrm{m}$ ), which may cause problems for further separation. For instance, the minimum size for conventional flotation is $\sim 5 \mu \mathrm{m}$, and this average particle size has not been reached during the heating experiments (Figure 8).

Furthermore, our work shows that Fe is not only enriched in all metal-bearing particles of all samples but also is still remaining in the surrounding matrix. Because of the heterogeneous distribution of Fe within all samples, beneficiation by magnetic separation is complicated or even impossible.

Moreover, the generally heterogeneous composition of the metal phases causes different chemical behavior that makes a flotation process challenging. Consequently, it is assumed that several different reagent regimes with several flotation steps may be necessary.

The particle size of the ground nodules also has an influence on the metallization degree, as our experiments suggested. If the nodule material is ground to less than $45 \mu \mathrm{m}$ the metallization degree is lower compared to the material that is ground to $200-315 \mu \mathrm{m}$.

\section{Conclusions}

This study shows that it is possible to enrich different target metals $(\mathrm{Ni}, \mathrm{Cu}, \mathrm{Co}, \mathrm{Mo})$ of $\mathrm{Mn}$ nodules that are dispersed heterogeneously in the nodule matrix into individual metal particles by selective reduction.

In this study we show that the Mn-mineral structures of Mn nodules treated with reagents like coke, sulfur and quartz under temperature $\left(1050-1100^{\circ} \mathrm{C}\right)$ break down and metals were released to form individual metal-rich particles. Those particles can be separated afterwards via conventional methods. However, current mineral processing methods such as density separation, magnetic separation, and flotation are inefficient for metal beneficiation for particle sizes below 10-20 $\mu \mathrm{m}$. The particles created in this study have a D $90<12.71 \mu \mathrm{m}$, too small for successful beneficiation via mineral processing steps. However, metal particles bigger than $20 \mu \mathrm{m}$ were also created. This indicates that with modified process parameters (e.g., longer reaction times in the rotary kiln and longer cooling time to try to form larger metal-rich particles, by varying the reactants), metal particle sizes can be increased. The metallization degrees achieved here (up to 80\%) and the high concentration of the target elements (e.g., $\mathrm{Fe}, \mathrm{Ni}, \mathrm{Cu}, \mathrm{Co}, \mathrm{Mo}$ ) in individual particles make the process very successful. The metallization of manganese is unwanted. To avoid the metallization of $\mathrm{Mn}$, relatively low reaction temperatures $\left(1050-1100^{\circ} \mathrm{C}\right)$ were used for the described tests. Higher temperatures $\left(\geq 1500^{\circ} \mathrm{C}\right)$ would result in higher Mn contents within the metal particles. 
The microprobe analyses of the individual metal-rich particles display a very heterogenic composition. However, the aim of this study was to create individual metal-rich particles that were as large as possible; the composition of the particles was of minor priority. Based on the created data, no composition pattern was identified. Further work and variation of the proportion of the used reactants (variation in the coke/sulfur mixture) is needed to improve the method.

However, further investigations are necessary to optimize this processing and should cover the following aspects: (1) longer reaction times between nodule material and the reactants within the rotary kiln to make sure that all of the materials react with each other and all metals will be released from the Mn-oxide structures, (2) longer cooling time to try to form larger metal-rich particles, (3) variation of the proportion of the used reactants (variation in the coke/sulfur mixture). Higher proportions of coke probably result in a higher amount of metal particles, which stick to the coke particles. This conglomerate of smaller metal particles and coarser coke particles could result in a significant density difference to the remaining metal-free particles. Investigations into whether these particles could be concentrated by density separation steps to create a metal-rich concentrate have to be conducted.

As the present work was conducted on a laboratory scale, a prediction on general energy and economic effects is not reasonable. If an improved process with sortable metal particles is developed in future studies, the overall processing chain has to be evaluated regarding environmental issues and energy and economic consequences. This also includes a follow-up metallurgical treatment for a metal particle concentrate that does not exist yet. Afterwards, this process can be compared to other pyro- or hydrometallurgical processes.

As more than $90 \%$ of the feed material will be rejected during future mineral processing of pre-treated polymetallic nodules, the question of waste disposal will be of importance, too. As the potential tailings will include significant amounts of manganese and iron, a possible implementation into ferromanganese production should be investigated. This would reduce the amount of tailings and the environmental impact of their disposal. Furthermore, the parts of the tailings that are not applicable for ferromanganese production should be studied in detail for any further use.

Author Contributions: Conceptualization, A.V.W., M.K., and T.K.; Methodology, A.V.W., M.K. and M.A.S.; Validation, A.V.W., M.K., T.K. and M.A.S.; Formal Analysis, A.V.W., M.K., and M.A.S.; Investigation, A.V.W., M.K., and M.A.S.; Resources, A.V.W., M.K., T.K., H.W. and M.A.S.; Data Curation, A.V.W. and M.K.; Writing-Original draft preparation, A.V.W. and M.K.; Writing-Review \& editing, A.V.W., M.K., and T.K.; Visualization, A.V.W. and M.K.; Supervision, M.K. and A.V.W.; Project Administration, T.K., H.W., and M.K.; Funding Acquisition, T.K.

Funding: This research was funded by internal BGR funding under the grant number A-0203008.A.

Acknowledgments: We thank Simon Goldmann and Christian Wöhrl for excellent support during the EPM analyses and Dominic Göricke for his help during SEM analyses at the Federal Institute for Geosciences and Natural Resources. We would also like to thank Stephan Kaufhold for discussions about the topic. Furthermore, we gratefully acknowledge the essential support during test works conducted at AMR of Klaus Hahn, Sebastian Blaum and Niklas Hermes-Böhlefeld. Additionally, we thank Bernd Friedrich and David Friedmann from IME, RWTH Aachen University for supporting the thermal pre-treatment at IME facilities.

Conflicts of Interest: The authors declare no conflict of interest.

\section{References}

1. Halbach, P.; Friedrich, G.; von Stackelberg, U. The Manganese Nodule Belt of the Pacific Ocean: Geological Environment, Nodule Formation, and Mining Aspects; Ferdinand Enke Verlag: Stuttgart, Germany, 1988; p. 254.

2. Von Stackelberg, U. Growth history of manganese nodules and crusts of the Peru Basin. In Manganese Mineralization: Geochemistry and Mineralogy of Terrestrial and Marine Deposits; Nicholson, K., Hein, J.R., Buhn, B., Dasgupta, S., Eds.; The Geological Society of London, Special Publication: Bath, UK, 1997; pp. 153-176.

3. De Lange, G.J.; Van Os, B.; Poorter, R. Geochemical composition and inferred accretion rates of sediments and manganese nodules from a submarine hill in the Madeira Abyssal Plain, eastern North Atlantic. Mar. Geol. 1992, 109, 171-194. [CrossRef] 
4. Jauhari, P.; Kodagali, V.; Sankar, S. Optimum sampling interval for evaluating ferromanganese nodule resources in the central Indian Ocean. Geo-Mar. Lett. 2001, 21, 176-182. [CrossRef]

5. Kuhn, T.; Wegorzewski, A.; Rühlemann, C.; Vink, A. Composition, formation, and occurrence of polymetallic nodules. In Deep-Sea Mining; Sharma, R., Ed.; Springer: Cham, Switzerland, 2017; pp. 23-63.

6. González, F.J.; Somoza, L.; León, R.; Medialdea, T.; de Torres, T.; Ortiz, J.; Merinero, R. Ferromanganese nodules and micro-hardgrounds associated with the Cadiz Contourite Channel (NE Atlantic): Palaeoenvironmental records of fluid venting and bottom currents. Chem. Geol. 2012, 310, 56-78. [CrossRef]

7. González, F.J.; Somoza, L.; Hein, J.R.; Medialdea, T.; León, R.; Urgorri, V.; Martín-Rubí, J.A. Phosphorites, Co-rich Mn nodules, and Fe-Mn crusts from Galicia Bank, NE Atlantic: Reflections of Cenozoic tectonics and paleoceanography. Geochem. Geophys. Geosyst. 2016, 17, 346-374. [CrossRef]

8. Hein, J.R.; Mizell, K.; Koschinsky, A.; Conrad, T.A. Deep-ocean mineral deposits as a source of critical metals for high- and green-technology applications: Comparisons with land-based resources. Ore Geol. Rev. 2013, 51, 1-14. [CrossRef]

9. Wegorzewski, A.V.; Kuhn, T. The influence of suboxic diagenesis on the formation of manganese nodules in the Clarion Clipperton nodule belt of the Pacific Ocean. Mar. Geol. 2014, 357, 123-138. [CrossRef]

10. Al Barazi, S.; Näher, U.; Vetter, S.; Schütte, P.; Liedtke, M.; Baier, M.; Franken, G. Commodity TopNews 53 (BGR): Cobalt from the DR Congo-Potential, Risks and Significance for the Global Cobalt Market; pp. 2-15. 2017. Available online: https:/ / www.deutsche-rohstoffagentur.de/DE/Gemeinsames/Produkte/ Downloads/Commodity_Top_News/Rohstoffwirtschaft/53_kobalt-aus-der-dr-kongo_en.pdf?_blob= publicationFile\&v=6 (accessed on 30 September 2018).

11. Rühlemann, C.; Kuhn, T.; Wiedicke, M.; Kasten, S.; Mewes, K.; Oicard, A. Current status of manganese nodule exploration in the German license area. In Proceedings of the ISOPE Ocean Mining Symposium, Maui, HI, USA, 19-24 June 2011; pp. 168-173.

12. Mero, J.L. The mineral Resources of the Sea; Elsevier: Amsterdam, The Netherlands, 1965; Volume 1.

13. Kuhn, T.; Rühlemann, C.; Wiedicke-Hombach, M. Developing a Strategy for the Exploration of Vast Seafloor Areas for Prospective Manganese Nodule Fields. In Marine Minerals: Finding the Right Balance of Sustainable Development and Environmental Protection; Zhou, H., Morgan, C.L., Eds.; The Underwater Mining Institute: Shanghai, China, 2012.

14. Rühlemann, C. Shipboard Scientific Party. In Cruise Report "BIONOD", Biodiversity, Geology and Geochemistry of the German and French Licence Areas for the Exploration of Polymetallic Nodules in the Equatorial NE Pacific; Federal Institute for Geosciences and Natural Resources (BGR): Hanover, Germany, 2012; p. 302.

15. van Wijk, J.M. Public Report: Blue Mining, Breakthrough Solutions for Mineral Extraction and Processing in Extreme Environments. 2018, pp. 3-30. Available online: http:/ / www.bluemining.eu/download/project_ results / public_reports/Blue-mining-Public-Report-2018.pdf (accessed on 30 September 2018).

16. Yamazaki, T.; Model mining units of the 20th century and the economies. Technical paper for ISA Workshop on Polymetallic Nodule Mining Technology-Current Status and Challenges Ahead. 2008, pp. 18-22. Available online: https:/ / www.isa.org.jm/files/documents/EN/Workshops/Feb2008/Yamazaki-Abst.pdf (accessed on 30 September 2018).

17. Von Heimendahl, M.; Hubred, G.L.; Fuerstenau, D.W.; Thomas, G. A transmission electron microscope study of deep-sea manganese nodules. Deep Sea Res. Oceanogr. Abstr. 1976, 23, 69-79. [CrossRef]

18. Burns, R.G.; Burns, V.M. The mineralogy and crystal chemistry of deep sea manganese nodules, a polymetallic resource of the twenty-first century. Philos. Trans. R. Soc. Lond. A 1977, 286, 283-301. [CrossRef]

19. Haynes, B.W.; Law, S.L.; Barron, D.C.; Kramer, G.W.; Maeda, R.; Pacific Manganese Nodules: Characterization and Processing. Bulletin (United States Bureau of Mines). 1985. Available online: https:/ / digicoll.manoa. hawaii.edu/techreports/PDF/USBM-679.pdf (accessed on 30 September 2018).

20. Burns, R.G.; Burns, V.M. Mechanism for nucleation and growth of manganese nodules. Nature 1975, 255, 130-131. [CrossRef]

21. Bodeï, S.; Manceau, A.; Geoffroy, N.; Baronnet, A.; Buatier, M. Formation of todorokite from vernadite in Ni-rich hemipelagic sediments. Geochim. Cosmochim. Acta 2007, 71, 5698-5716. [CrossRef]

22. Wegorzewski, A.V.; Kuhn, T.; Dohrmann, R.; Wirth, R.; Grangeon, S. Mineralogical characterization of individual growth structures of Mn-Nodules with different $\mathrm{Ni}+\mathrm{Cu}$ content from central Pacific Ocean. Am. Mineral. 2015, 100, 2497-2508. [CrossRef] 
23. Peacock, C.L.; Sherman, D.M. Sorption of Ni by birnessite: Equilibrium controls on Ni in seawater. Chem. Geol. 2007, 238, 94-106. [CrossRef]

24. Peacock, C.L.; Sherman, D.M. Crystal-chemistry of Ni in marine ferromanganese crusts and nodules. Am. Mineral. 2007, 92, 1087-1092. [CrossRef]

25. Peacock, C.L. Physiochemical controls on the crystal-chemistry of Ni in birnessite: Genetic implications for ferromanganese precipitates. Geochim. Cosmochim. Acta 2009, 73, 3568-3578. [CrossRef]

26. Sherman, D.M.; Peacock, C.L. Surface complexation of $\mathrm{Cu}$ on birnessite $\left(\delta-\mathrm{MnO}_{2}\right)$ : Controls on $\mathrm{Cu}$ in the deep ocean. Geochim. Cosmochim. Acta 2010, 74, 6721-6730. [CrossRef]

27. Manceau, A.; Lanson, M.; Takahashi, Y. Mineralogy and crystal chemistry of Mn, Fe, Co, Ni, and Cu in a deep-sea Pacific polymetallic nodule. Am. Mineral. 2014, 99, 2068-2083. [CrossRef]

28. Liu, L.; Min, M.; Liu, F.; Yin, H.; Zhang, Y.; Qiu, G. Influence of vanadium doping on the supercapacitance performance of hexagonal birnessite. J. Power Sources 2015, 277, 26-35. [CrossRef]

29. Wegorzewski, A.V.; Grangeon, S.; Webb, S.; Kuhn, T. Mineralogical transformations in polymetallic manganese nodules and the changes in the crystal-chemistry of $\mathrm{Ni}, \mathrm{Cu}$ and $\mathrm{Co}$ upon burial in sediments. In preparation.

30. Blöthe, M.; Wegorzewski, A.V.; Müller, C.; Simon, F.; Kuhn, T.; Schippers, A. Manganese-Cycling Microbial Communities Inside Deep-Sea Manganese Nodules. Environ. Sci. Technol. 2015, 49, 7692-7700. [CrossRef] [PubMed]

31. Leonhardt, H. Untersuchungen zur Aufbereitbarkeit von Manganknollen. Ph.D. Thesis, Rheinisch-Westfälische Technische Hochschule Aachen, Aachen, Germany, 1979.

32. Vasil'chikov, N.V.; Shirer, G.B.; Matsepon, Y.A.; Krasnykh, I.F.; Grishankova, E.A. Iron-Manganese Nodules from the Ocean Floor-Raw Materials for the Production of Cobalt, Nickel, Manganese, and Copper. Tsvet. Metally. 1968, 9, 46-49.

33. Beck, R.R.; Messner, M.E. Copper, Nickel, Cobalt and Molybdenum recovery from deep sea nodules. In Copper Metallurgy; AIME: New York, NY, USA, 1970; pp. 70-82.

34. Friedmann, D.; Friedrich, B. Optimized Slag Design for Maximum Metal Recovery during the Pyrometallurgical Processing of Polymetallic Deep-Sea Nodules. In Advances in Molten Slags, Fluxes, and Salts: Proceedings of the 10th International Conference on Molten Slags, Fluxes and Salts; Springer: Cham, Switzerland, 2016; pp. 97-104.

35. Abramovski, T.; Stefanova, V.P.; Causse, R.; Romanchuk, A. Technologies for the processing of polymetallic nodules from Clarion Clipperton Zone in the Pacific Ocean. J. Chem. Technol. Metall. 2017, 52, 258-269.

36. Grill, R. Igneous Rocks and Processes: A Practical Guide; Wiley-Blackwell: Hoboken, NJ, USA, 2010; p. 169.

37. Gu, Y. Automated Scanning Electron Microscope based Mineral Liberation Analysis: An Introduction to JKMRC/FEI Mineral Liberation Analyser. J. Miner. Mater. Charact. Eng. 2003, 2, 33-41. [CrossRef]

38. Fandrich, R.; Gu, Y.; Burrows, D.; Moeller, K. Modern SEM-based mineral liberation analysis. Int. J. Min. Proc. 2007, 84, 310-320. [CrossRef]

39. Füchtjohann, L.; HuK Umweltlabor GmbH, Wenden-Hünsborn, Germany. Personal communication, 2016.

40. Sridhar, R. Thermal Upgrading of Sea Nodules. JOM 1974, 12, 18-22. [CrossRef]

41. Atkins, A.L.; Shaw, S.; Peacock, C.L. Release of Ni from birnessite during transformation of birnessite to todorokite: Implications for Ni cycling in marine sediments. Geochim. Cosmochim. Acta 2016, 189, 158-183. [CrossRef]

42. Rziha, T. Synthese, Charakterisierung und Kristallchemie von Manganoxidphasen. Ph.D. Thesis, Fakultät für Geowissenschaften der Ruhr-Universität Bochum, Bochum, Germany, 1997; p. 155.

(C) 2018 by the authors. Licensee MDPI, Basel, Switzerland. This article is an open access article distributed under the terms and conditions of the Creative Commons Attribution (CC BY) license (http://creativecommons.org/licenses/by/4.0/). 